\title{
COMPLETE RESPONSE OF METASTATIC RENAL CANCER WITH DENDRITIC CELL VACCINE
}

\author{
MARCOS DALL'OGLIO, MIGUEL SROUGI, JOSÉ A.M. BARBUTO \\ Discipline of Urology, Paulista School of Medicine, Federal University of São Paulo, UNIFESP, Sírio \\ Libanês Hospital of São Paulo and Department of Immunology, ICB-USP, São Paulo, SP, Brazil
}

\begin{abstract}
Introduction: We report a case of metastatic renal cell carcinoma that presented involution following therapy with dendritic cells.

Case Report: Male, 51-year old patient underwent left radical nephrectomy in September 1999 due to renal cell carcinoma, evolved with recurrence of the neoplasia in January 2002, confirmed by resection of the lesion. A vaccine therapy based on dendritic cells was then performed during 5 months ( 4 applications). After this period, there was occurrence of new lesions, whose resection revealed areas of necrosis and inflammatory infiltrate.

Discussion: The outcome of renal cell carcinoma is influenced by prognostic factors that confer more aggressive tumor characteristics. However, in cases of recurrence, the systemic therapy with dendritic cells-based vaccine can be associated with a better outcome with regression of disease.
\end{abstract}

Key words: kidney neoplasms; carcinoma; neoplasms metastasis; dendritic cell; vaccines

Int Braz J Urol. 2003; 29: 517-519

\section{INTRODUCTION}

Annual estimates show that the diagnosis of renal cell carcinoma (RCC) has increased, with surgical resection of the localized tumor being the best therapeutic approach. However, the occurrence of metastases following surgery is not uncommon, which generates a poor prognosis. Periodically, positive responses with regression of RCC metastases are published in small series (1), unfortunately, in practical terms, such results are not reproduced. The immunotherapy with interleukin and interferon presents a high toxicity and short-lived responses in $10 \%$ to $20 \%$ of cases (1), for this reason, the systemic therapy in this group of patients remains a huge challenge.

Recent works aimed to stimulate the immune response through transplantation of allogeneic lymphocytes (2) and vaccine of dendritic cells hybridized with cells from the tumor itself (3) are a new alternative to these patients.
We present a case report with involution of metastatic lesions due to RCC following therapy with hybrid dendritic-tumor cells.

\section{CASE REPORT}

Male, 51-year old patient underwent left radical nephrectomy due to renal cell carcinoma, clear cell type and nuclear grade III, in September 1999. In January 2002, he presented retroperitoneal recurrence in periaortic lymph node whose resection showed to be a metastatic RCC (Figure-1,A). The resection product was used for preparing a vaccine of hybrid dendritic-tumor cells. Vaccines were applied in the region of inguinal, with applications performed every 6 weeks, in the period from February 27, 2002 to June 25,2002 . In June 2002, a left para-aortic mass and a hepatic nodule appeared (Figure-2), which upon surgical resection were shown to consist solely of necrosis and inflammatory infiltrate (Figure-1, B). De- 


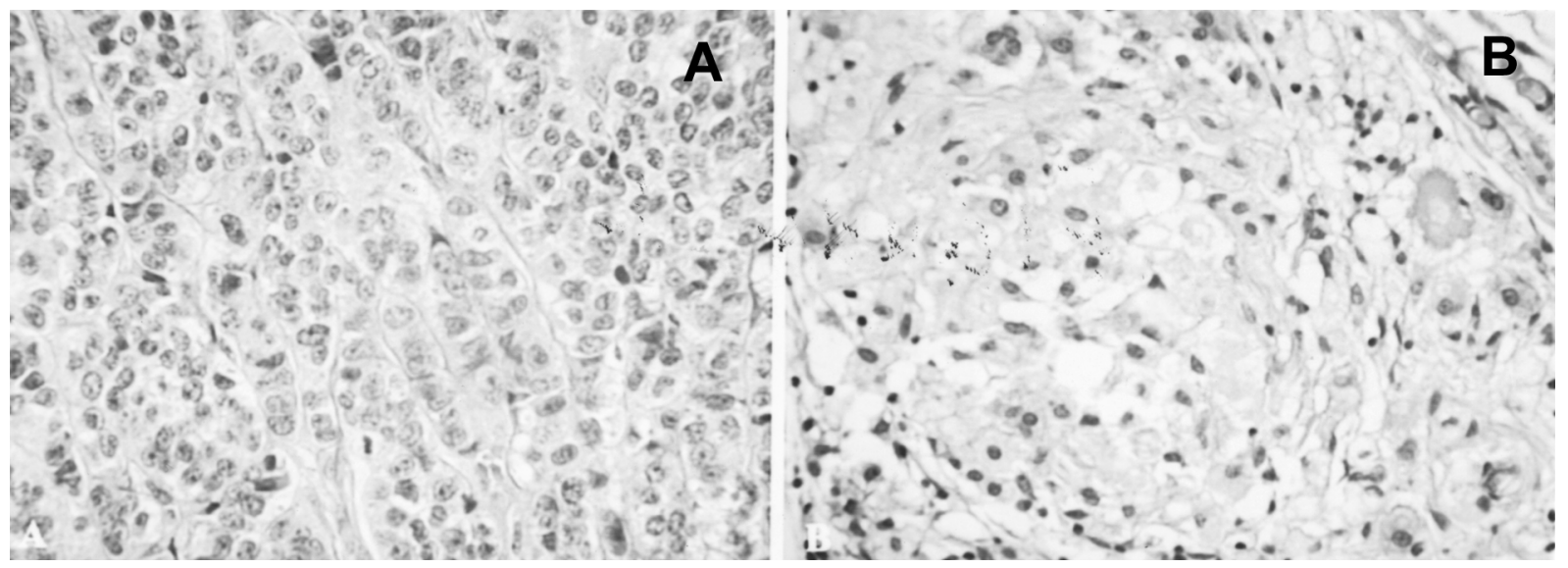

Figure 1 - A) Neoplasia constituted by strings of pleomorphic cells characterizing renal cell carcinoma metastatic to retroperitoneal lymph node. B) Post-treatment. The resected retroperitoneal lymph node reveals epithelioid granuloma, fibrosis and absence of residual tumor.

spite the initial good response, after 6 months, in December 2002, new secondary lesions appeared in lungs and abdomen. At this moment, a new trial for salvage with cytotoxic chemotherapy was performed, with unsatisfactory response and progression of disease.

\section{DISCUSSION}

Reports of spontaneous regression of metastatic RCC due to antitumor cytotoxic reaction of $\mathrm{T}$ lymphocytes demonstrate the importance of the im- mune system in controlling this disease's devastating course. Despite the advances in identification of genetic anomalies related to RCC, we still have limitations in systemic therapy, for this reason, researchers are trying therapies with immunologic reinforcement.

Thus, despite the diversity of treatments (1), the advanced renal cancer remains resistant to systemic therapy, and the identification of new agents with antitumor activity remains a priority in every research center, considering that to this moment there was not a long-lasting response with current therapies. Nevertheless, vaccination with hybrid cells is
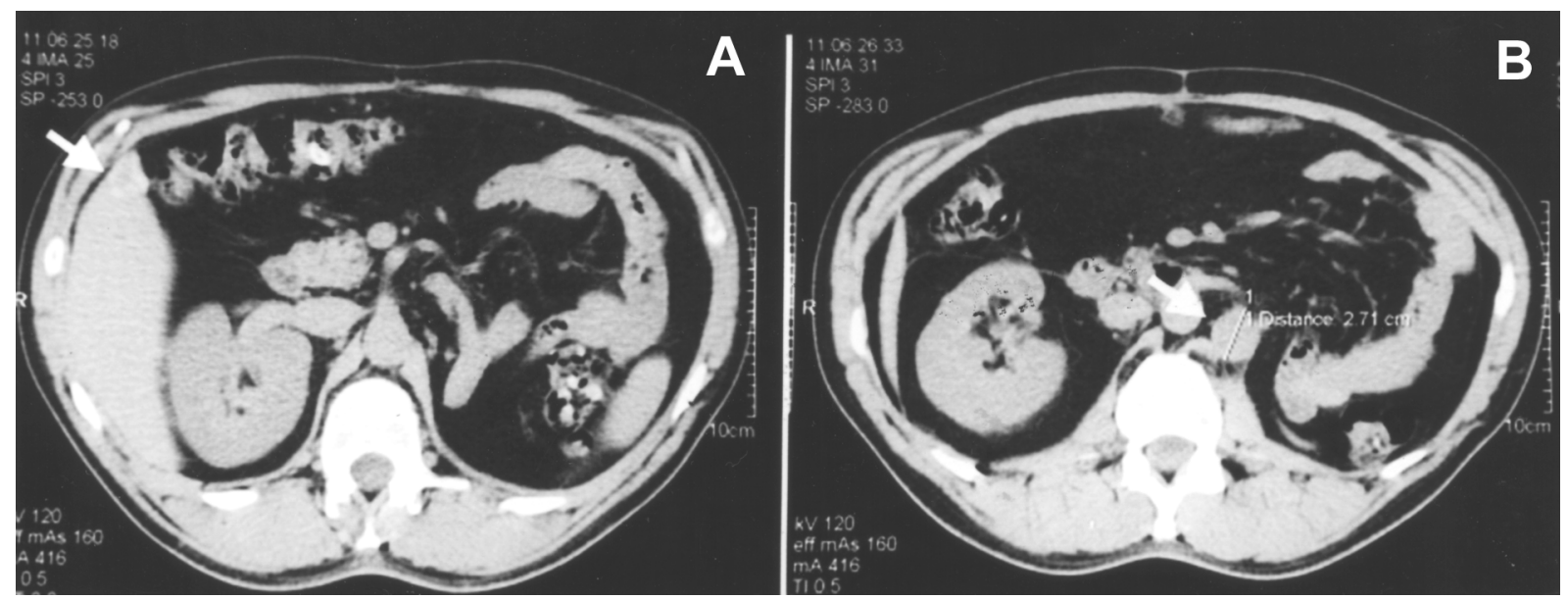

Figure 2 - A) Hepatic nodule (arrow); B) Left para-aortic lesion (arrow). 
showing encouraging responses in immune therapy for advanced RCC $(2,3)$.

Kugler et al. (3) had surprising results when submitting 17 patients with metastatic RCC to immune therapy with a vaccine of hybrid dendritic-tumor cells, achieving $41 \%$ of response, with 4 full remissions of metastases, 2 partial remissions and a mixed response, in addition to 2 patients with stabilization of disease, with a mean follow-up of 13 months. This treatment has the advantage of presenting no adverse effects, providing a high quality of life to patients, in contrast to the usual therapy with cytokines that, in spite of presenting objective responses, is associated with serious side effects, which can lead even to death.

This case report tries to illustrate an effective response to this immune therapy, which, following a dramatic initial response proved by surgical resection and disease control for 6 months, presented a new systemic recurrence with active disease. Considering the stabilization of the disease, even if for a short period, we see this as an encouraging response, in view of the aggressive character of RCC.

These modalities of genetic therapies with the use of vaccines can have a great therapeutic value in the future.

Financial Support: FAPESP (01/02339-8)

\section{REFERENCES}

1. Motzer R, Russo P: Systemic therapy for renal cell carcinoma. J Urol. 2000; 163: 408-17.

2. Childs R, Chernoff A, Contentin N, Bahceci E, Schrump D, Leitman S, et al.: Regression of metastatic renal cell carcinoma after nonmyeloablative allogeneic peripheral- blod stem-cell transplantation. New Engl J Med. 2000; 343: 750-8.

3. Kugler A, Stuhler G, Walden P, Zöller G, Zobywalski A, Brossart P, et al.: Regression of human metastatic renal cell carcinoma after vaccination with tumor celldendritic cell hybrids. Nature Med. 2000; 6: 332-6.

Received: March 10, 2003

Accepted after revision: October 6, 2003

\author{
Correspondence address: \\ Dr. Marcos Dall'Oglio \\ Rua Manoel da Nóbrega, 853 casa 22 \\ São Paulo, SP, 04001-084, Brazil \\ Fax: + $55113885-0658$ \\ E-mail: marcosdalloglio@uol.com.br
}

